\title{
Evaluation of bearing capacity of reinforced concrete box ribbed arch bridge based on dynamic load test
}

\author{
Mao $\mathrm{He}^{1}$, Xin Fu${ }^{2}$ and Shunchao Chen ${ }^{1 *}$ \\ ${ }^{1}$ College of Civil Engineering, Southwest Forestry University, Kunming, Yunnan, 650224, China \\ ${ }^{2}$ College of Civil Engineering, Southwest Forestry University, Kunming, Yunnan, 650224, China
}

\begin{abstract}
Dynamic load test is to measure the natural vibration characteristics of the bridge structure or the forced vibration characteristics under dynamic load, and to evaluate the driving performance, driving safety and comfort of the bridge through dynamic load test. In order to evaluate the stress state and working performance of a reinforced concrete box-ribbed arch bridge, the load test of the bridge is carried out. Dynamic load test is used to test the inherent fundamental frequency, damping ratio and impact coefficient of the bridge through pulsation test and sports car test. Through the experiment with the key parts of the stress (strain) and displacement load and other important data, through analysis and study, the comprehensive analysis of the phenomenon of calculation and test, a comprehensive performance evaluation structure and function whether meet the design requirements, to provide technical basis for the safety of the bridge operation, and provide the original material for the bridge maintenance and management in the future.
\end{abstract}

\section{Introduction}

Arch is a kind of structure bearing type with long history and wide application. Under the vertical load [1], the arch is mainly under axial compression, and the reinforced concrete box ribbed arch bridge can be built by making full use of the concrete material with excellent compressive performance.

The arch rib is composed of two or more separate parallel arch ribs and the roadway plate supported by the column and beam set on the arch rib [2]. Because the arch rib reduces the dead weight of arch ring very well, so the constant load internal force of arch rib is small, live load internal force is larger, with the advantages of saving material, reducing the dead weight, reducing the lower amount of engineering, beautiful appearance, so it should be used in large, medium span reinforced concrete structure.

Along with the economic development of the traffic volume increasing, local service performance of highway Bridges is generally faced with higher requirements [3-4], under the condition of market economy, to supervise the quality of bridge not only can't fade, and must be strengthened, the quality issues at stake, must be the quality of the new bridge inspection, to ensure the performance stability of the bridge during service.

\section{Basic information of bridge}

Because of the need to build a power station, the original part of the road is located in the submerged range, due to the need of was built, on the bridge is built, the bridge is 1 to $40 \mathrm{~m}$ rib reinforced concrete box arch bridge, bridge span $45 \mathrm{~m}$, design speed is $20 \mathrm{~km} / \mathrm{h}$, and design load level for highway - grade I, design flood frequency was $1 / 50$, bridge seismic fortification intensity of for IIV, bridge overall width $9.5 \mathrm{~m}$, width $8.5 \mathrm{~m}$, bridge arrangement as follows: $0.5 \mathrm{~m}$ (crash barrier) $++0.5 \mathrm{~m}$, $8.5 \mathrm{~m}$ (driveway) (crash barrier).

The Midas Civil bridge finite element analysis software was used for the calculation tool, and the arch ribs were simulated by beam element. The characteristic value of the bridge was analyzed by applying dynamic load to the model to obtain the natural vibration characteristics and impact coefficient, and the dynamic characteristics of the bridge were compared with the measured values after the real bridge was loaded.

\section{Test items and test methods}

\subsection{Testing the natural vibration characteristics of the structure}

The natural vibration characteristics of the bridge can be obtained by analyzing the free vibration response curve of the bridge. The excitation method is environmental excitation method, and the testing instrument is DH5907N wireless modal testing system tested by Donghua test. The ambient vibration method (pulsating method) is a method to identify the natural vibration characteristics of the bridge structure by measuring the micro-amplitude vibration caused by random excitation

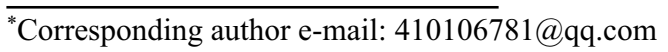


such as wind load and ground pulsation when the bridge deck is free of any traffic load and there is no regular vibration source near the bridge site.

\subsection{Bridge driving dynamic response test}

Under the action of driving load, the resistance strain gauge is adopted to test the dynamic strain response of the measuring point in cooperation with Donghua DH5922 dynamic signal testing and analysis system. The vibration signal testing and analysis software is used to store, amplify, filter and analyze the signal. In this way, barrier-free sports cars are adopted. In other words, in the case of barrier-free bridge deck, a test vehicle weighing about $450 \mathrm{KN}$ is adopted as a dynamic load test vehicle. The test vehicle travels uniformly along the lane at different speeds to test the dynamic strain at the L/2 section of the hollow plate.

\subsection{Arrangement of measuring points}

According to the dynamic response of the bridge under the excitation signal and the sports car test of vibration signals, the bridge first, second order and third order theory of vertical vibration frequency, damping ratio, the structure from the basic frequency of vibration test values and the finite element software to calculate the theoretical value shown in table 1, the bridge bridge first and second order and third order theory of vertical vibration model and the measured vibration mode as shown in figure 2 to figure 3 , respectively.

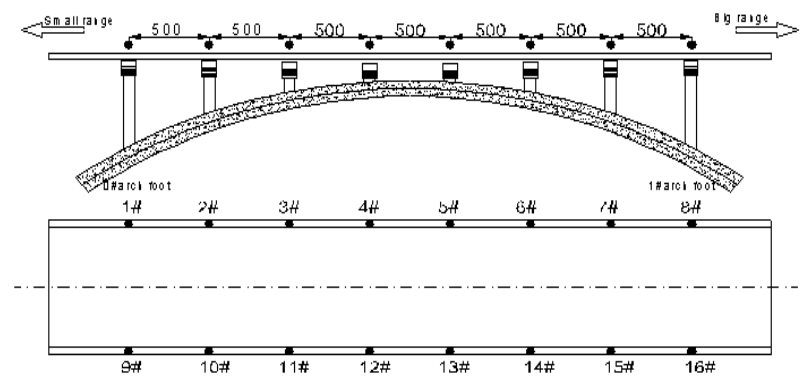

Figure 1. The modal test layout (unit: $\mathrm{cm}$ )

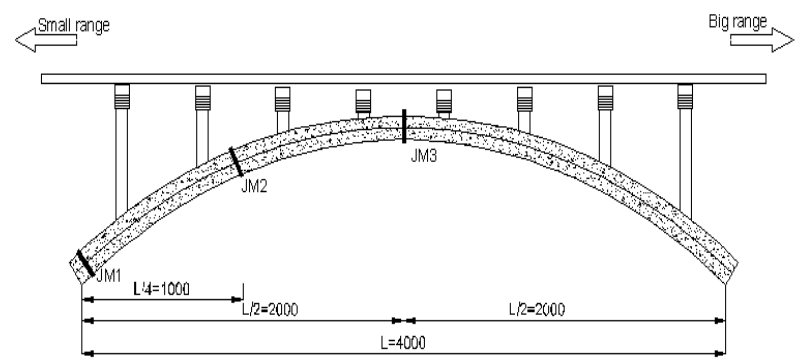

Figure 2. Test section layout (unit: $\mathrm{cm}$ )

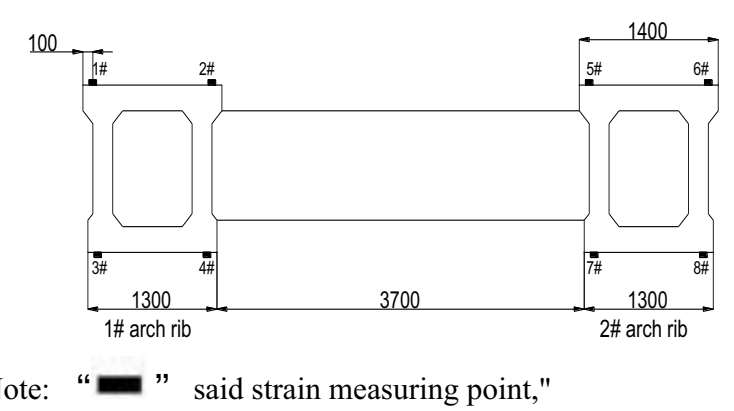

Figure 3. Sectional strain measuring point layout (unit: $\mathrm{cm}$ )

\section{Dynamic load test of bridge}

\subsection{Fluctuation test}

According to the dynamic response of the bridge under the excitation signal and the sports car test of vibration signals, the bridge first, second order and third order theory of vertical vibration frequency, damping ratio, the structure from the basic frequency of vibration test values and the finite element software to calculate the theoretical value shown in table 1 , the bridge bridge first and second order and third order theory of vertical vibration model and the measured vibration mode as shown in figure 4 to figure 9 .

Table 1. Theoretical and measured fundamental frequency

\begin{tabular}{|c|c|c|c|c|}
\hline Order & $\begin{array}{c}\text { Theoretical } \\
\text { fundamental } \\
\text { frequency } /(\mathrm{Hz})\end{array}$ & $\begin{array}{c}\text { The measured } \\
\text { fundamental } \\
\text { frequency } /(\mathrm{Hz})\end{array}$ & $\begin{array}{c}\text { Measured } \\
\text { damping } \\
\text { ratio } /(\%)\end{array}$ & $\begin{array}{c}\text { Measured/ } \\
\text { Theoretical }\end{array}$ \\
\hline Order-1 & 5.943 & 5.981 & 0.009 & 1.006 \\
\hline Order-2 & 6.076 & 7.324 & 0.007 & 1.205 \\
\hline Order-3 & 7.005 & 7.886 & 0.009 & 1.126 \\
\hline
\end{tabular}

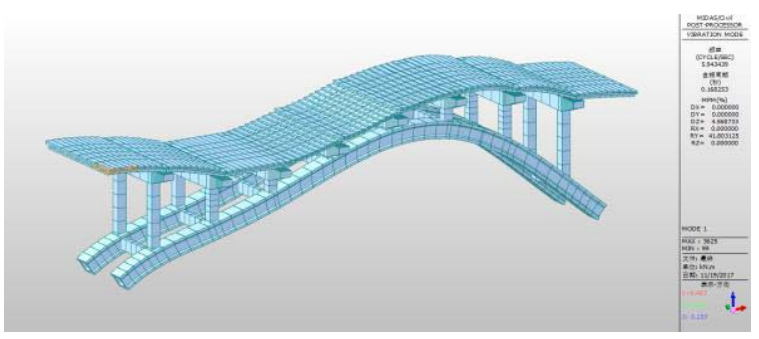

Figure 4. Theoretical mode of order-1 vertical bending

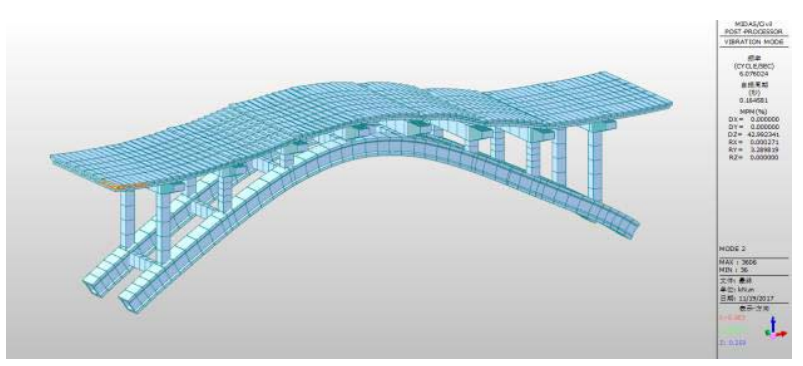

Figure 5. Theoretical mode of order-2 vertical bending 


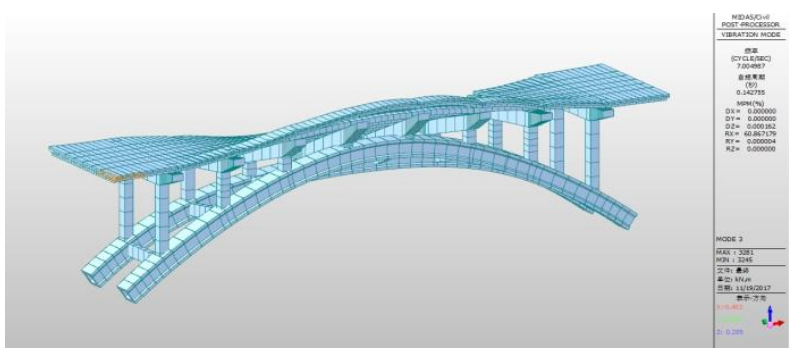

Figure 6. Theoretical mode of order-3 vertical bending

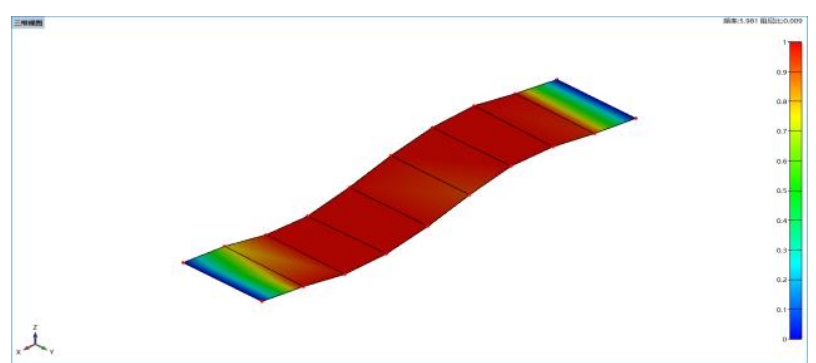

Figure 7. Measured vibration mode of order-1 vertical bending

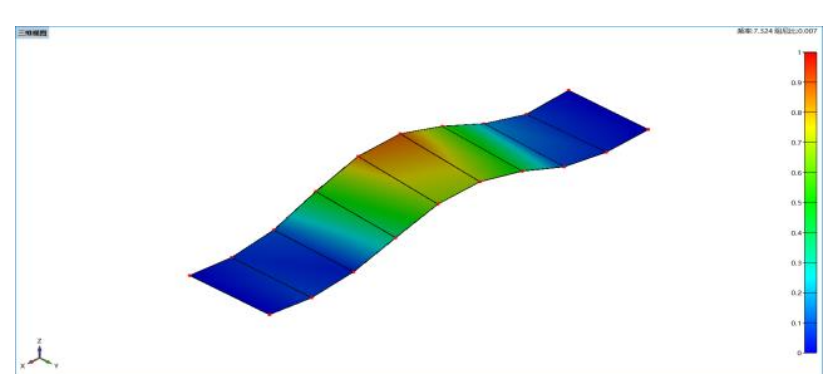

Figure 8. Measured vibration mode of order-2 vertical bending

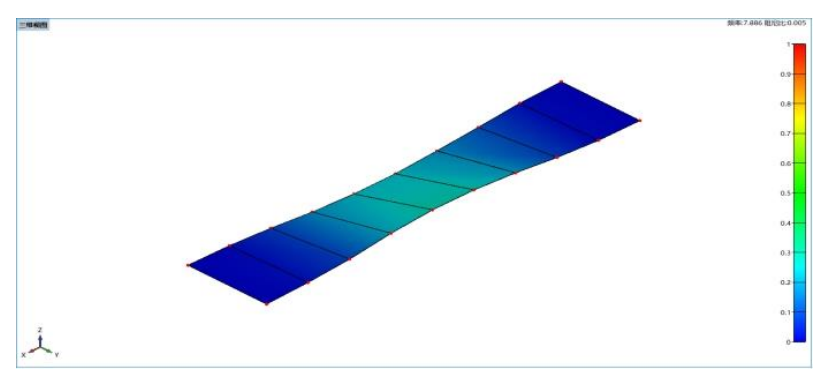

Figure 9. Measured vibration mode of order-3 vertical bending

According to the relevant provisions in Article 5.9 of Highway Bridge Load Bearing Capacity Testing and Evaluation Procedures (JTG /T J21-2011) [5], it is advisable to determine the evaluation scale of natural vibration frequency according to the ratio of measured natural vibration frequency FMI and theoretical natural vibration frequency FDI. The ratios of the measured and theoretical frequencies of the first and second order vertical vibrations of the bridge were 1.006, 1.205 and 1.126 , respectively, and the corresponding measured damping ratios were $0.009,0.007$ and 0.009 , respectively, which were within a reasonable range and the evaluation scale of natural vibration frequency across the test was 2 , indicating that the dynamic stiffness of the structure met the design requirements.

\subsection{Barrier-free driving experiment}

To test the bridge across all of the whole bridge, the test load vehicles in without any obstacle, with 1 load car always weighs about $450 \mathrm{kn}$, with $10 \mathrm{~km} / \mathrm{h}, 20 \mathrm{~km} / \mathrm{h}, 30$ $\mathrm{km} / \mathrm{h}$ speed past the bridge span structure, with China DH5922 dynamic signal collection and analysis of test data test and analysis system, determination of bridge span structure in operation under the action of vehicle load and dynamic response. The time-history curve is shown in figure 10 to figure 12. According to the theoretical calculation of fundamental frequency, the theoretical calculation of the impact coefficient of the bridge is 0.299 . The measured dynamic strain and dynamic increment coefficient are shown in Table 2.

Table 2. Test value of impact coefficient

\begin{tabular}{|c|c|c|c|}
\hline \multirow{2}{*}{$\begin{array}{c}\text { The test } \\
\text { section }\end{array}$} & $\begin{array}{c}\text { Driving speed } / \\
(\mathrm{km} . \mathrm{h}-1)\end{array}$ & $\begin{array}{c}\text { Maximum } \\
\text { dynamic strain } \\
/(\mu \varepsilon)\end{array}$ & $\begin{array}{c}\text { Impact factor } \\
/(1+\mu)\end{array}$ \\
\hline \multirow{3}{*}{ JM3 } & 10 & 9 & 0.076 \\
\cline { 2 - 4 } & 20 & 8 & 0.103 \\
\cline { 2 - 4 } & 30 & 11 & 0.144 \\
\hline
\end{tabular}

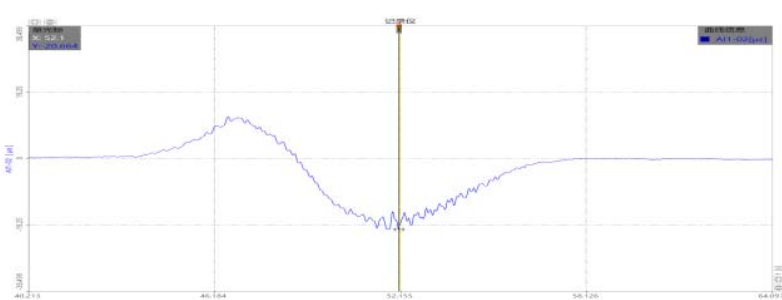

Figure 10. Dynamic strain time-history curve of barrier-free driving at $10 \mathrm{~km} / \mathrm{h}$

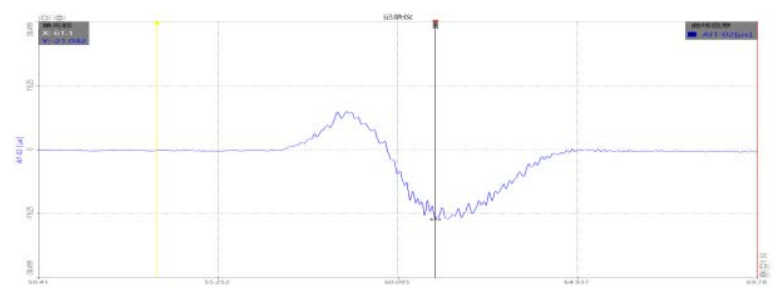

Figure 11. Dynamic strain time-history curve of barrier-free driving at $20 \mathrm{~km} / \mathrm{h}$

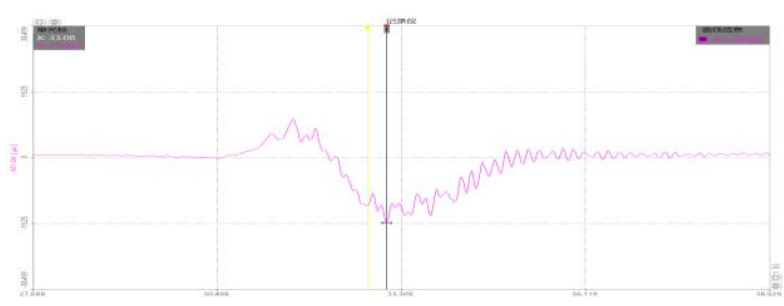

Figure 12. Dynamic strain time-history curve of barrier-free driving at $30 \mathrm{~km} / \mathrm{h}$

It can be seen from the above table that the maximum dynamic coefficient of barrierless driving test is 1.144 , the corresponding dynamic strain increment coefficient is 0.144 , and the dynamic increment coefficient is all smaller than the theoretical calculation impact coefficient of 0.299. It can be seen from the above figure 
that the bridge has a normal running curve and is relatively comfortable. It shows that the impact coefficient of the bridge is small and the bridge deck is in good condition.

In the existing load-bearing capacity evaluation methods, most structures can be evaluated rapidly and effectively. According to the relationship between the static and dynamic performance of the structure, (,) was used as the comprehensive evaluation index of static and dynamic performance, which was calculated according to formula (1) [6].

$$
\beta(\eta, \mu)=\frac{\eta\left(1+\mu_{M}\right)}{\eta\left(1+\mu_{T}\right)}
$$

In the equation: $\beta(\eta, \mu)$ is the comprehensive evaluation index of static and dynamic function; The is the average value of relative check coefficient of each cross section under static load. Is the measured impact coefficient; The theory is used to calculate the impact coefficient. It can be calculated that $\beta(\eta, \mu)=0.69<1$ and the bridge structure meets the requirements of carrying capacity.

\section{Conclusions}

1) The ratio of measured frequency to theoretical frequency and the corresponding measured damping ratio of the first, second and third order vertical vibration of the bridge are all within a reasonable range, which indicates that the dynamic stiffness of the structure meets the design requirements

2) The comprehensive evaluation index of static and dynamic $(\eta, \mu)=0.69<1$, the bridge structure meets the requirements of carrying capacity

3) The method used in this experiment can be used to accurately measure the natural vibration characteristics and running state of the bridge. The method is relatively simple and practical, which is worth popularizing

4) To sum up, the bridge meets the design requirements and can meet the local use needs.

\section{References}

1. $\mathrm{Xu} \mathrm{Y.} \mathrm{(2013)} \mathrm{Origin} \mathrm{of} \mathrm{Arch} \mathrm{Bridges} \mathrm{and}$ Development of Stone Arch Bridges [J]. World Bridge, 41(3):85-92.

2. Tong Lin, PENG Yibin. Load Test research of Reinforced concrete Ribbed arch Bridge in service [J]. Highway and Motor Transport,2012(05):176180.

3. Yang Gen-jie. Analysis of mechanical property of sin-gle arch rib prestressed concrete beam arch combina-tion bridge[J]. Journal of Railway Engineering Soci-ety, 2017, 34(6):37-42.

4. Tong Qiuguo. Disease analysis and Reinforcement technology research of stone arch Bridges in service [D]. Changsha: Central South University of Forestry and Technology, 2011.
5. Ministry of Transport of the People's Republic of China, Specification for inspection and evaluation of load-bearing capacity of highway bridges: JTG/TJ21-2011 [S]

6. Ministry of Transport of the People's Republic of China, Specifications for load testing of highway bridges (Draft for comments): [S] 